\title{
Family type, ethnicity and under-five mortality in Nigeria
}

\author{
Gbadebo, Babatunde M. ${ }^{1}$, Bamiwuye S.O. ${ }^{2}$ \& Bisiriyu L.A ${ }^{2}$ \\ ${ }^{1}$ Department of Epidemiology and Medical Statistics, College of Medicine, \\ University of Ibadan, Oyo State, Nigeria \\ ${ }^{2}$ Department of Demography and Social Statistics, Obafemi Awolowo University, \\ lle-Ife, Nigeria. \\ Email: tundegbadebo2005@yahoo.com
}

\begin{abstract}
Background: High rate of under-five mortality (UFM) in Nigeria is an impediment to national development. This study examined the influence of family type and ethnicity on UFM.

Data Source and Methods: The study was cross-sectional and employed the 2013 Nigeria Demographic and Health Survey dataset. The survey utilised a stratified three-stage cluster sampling procedures in interviewing 31,828 women of childbearing age. Data were analysed using Chi-square test, Brass and Cox-proportional hazard models.

Results: UFM rates were 92, 119 and 196 deaths per 1000 live births among Yoruba, lgbo/lbo and Hausa/Fulani respectively. On overall, single-parent who were Hausa/Fulani women reported the highest deaths $\left(265 /{ }^{\prime} 000\right)$ and the polygamous lgbo women reported the lowest $\left(2 /{ }^{\prime} 000\right)$. UFM is lowest among the lgbo/lbo while single parenting impact on UFM more among Hausa/Fulani than other ethnic groups.

Conclussion: Family type and ethnicity were associated with UFM. Measures to reduce UFM should target single-parenting and the Hausa/Fulanis
\end{abstract}

Keywords: Ethnic groups, Family Type, Mortality, Nigeria

\section{Introduction}

Improving child well-being is a key global public health goal. This is because the well-being of a child has implications on the health of the future generation and national development. Childhood mortality remains a problem in Nigeria. In the past few decades, there has been persisted reporting of high infant and childhood mortality rates in Nigeria. Nigeria was even identified as one of the countries that failed to meet the 4th Millennium Development Goals of reducing under-five mortality by two-third (Oleribe \& Taylor-Robinson, 2016). Nigeria with under-five mortality rate of 128 deaths per I 000 live birth has the highest child mortality in sub-Saharan Africa (NPC Nigeria and ICF Int., 20I4; World Bank, 2010). Globally, Nigeria alone accounted for II percent of the under-five mortality after India which shares 24 per cent of the burden of the world's under-five mortality (UNICEF, 20I2).

In the previous studies, under-five mortality have been linked with socio-economic characteristics of the mothers (Omaribet et al 2007, Adedini et al, 20II); others linked under-five mortality with family type, while some authors associated under-five mortality with ethnicity (Adedini et al, 20I I; Fayehun \& Omololu , 20II). Among researchers linking under-five mortality with family type, some found single-parenting to be a risk factor of under-five mortality (Shudy, Almeida, Ly, ... MD, 2006; Bramlett and Blumberg, 2007; Wen, 2008; Lesley, 2008; PRB, 2010; Doctor, 20II). Other studies linked the risks of under-five mortality to polygamous practice (Omariba and Boyle, 2007; Kayode, Adekanmbi and Uthman, 20I2, Titilayo, Anuodo \& Palamuleni, 2017). In Nigeria, several cultural practices such as childfeeding patterns and perception of the causes of child illnesses and deaths play significant roles on the health and survival of children (Ogunjuyigbe, 2004; Jegede et al, 2006; Adedini et al, 20 I I)).

In order to reduce the burden of under-five mortality in Nigeria, various initiatives and efforts such as Safe Motherhood Initiatives, National Partnership for Maternal Newborn and Child Health, and Saving One Million Lives Initiative were put in place but these only yielded minimal results. However, in order for the Sustainable Development Goal of reducing under-five mortality rate by twothirds not to be at deadlock progress towards reducing under-five mortality must be accelerated. This should include research on under-five mortality. However, this study only explores the variables (family type and ethnicity) as independent entities related to under-five mortality. The possibility of influence between the two has not been investigated. 
This is because social household behaviour across different family type can vary between different ethnic groups. Previous studies, for instance, Adedini et al (2015) only looked at effects of ethnic differentials on under-five mortality in Nigeria, while Titilayo and his colleagues examined the effects of family type and domestic violence on under-five mortality in Nigeria (Titilayo et al, 2017). None of their studies focused on the combined effect of ethnicity and family type on under-five mortality. It is against this backdrop that this paper aimed at examining the relationship between family type, ethnicity and under-five mortality.

\section{Literature review}

Relevant literatures on under-five mortality were cited from relevant published articles, Google scholar, PubMed, among others. From the available literatures, under-five mortality in Nigeria was estimated as 192 deaths per 1000 live births in 1990 , declining to 128 deaths per thousand live births in 2013 (MDG Reports, 2010; UN-IGME, 20II; NPC Nigeria and ORC Macro, 1991, 2000, 2004; NPC Nigeria and ICF Macro, 2009 and NPC Nigeria and ICF Int., 20I4). This decline represents 33.3 percent decrease on the under-five mortality reported in 1990, an average of I.5 annual decrease as against an average of 4.4 annual decrease suggested by the MDG 4 (UN-IGME, 20I0). Regional distributions show that Northern regions are having higher rates of under-five mortality than the Southern regions (NPC Nigeria and ICF Int., 20I4).

Several factors accounted for high childhood morbidity and mortality in sub-African countries. Studies about the causes of under-five mortality in sub-Saharan Africa countries indicated that more than 70 percent of childhood illnesses and diseases can be prevented by simple preventable vaccines (Gyimah, 2002; WHO. 2018). In Nigeria, morbidity and mortality among children in their early childhood are attributed to three common causes, which are fever, diarrhoea and cough (Kandala et al, 2007). Undernutrition and maternal health act as underlying factors in some of the deaths (Bryce, Boschi-Pinto, Shibuya, Black, and the WHO, 2005).

Studies have linked under-five mortality to differential maternal, socio-economic and demographic characteristics including age, education, household wealth status, occupation, place of residence, family type and ethnicity (Mutunga, 2004; Omariba and Boyle, 2007; Adedini et al, 2015; Niragire et al, 2017). Researches on the relationship between under-five mortality and family type showed mixed reactions. Studies have established that the chances of mortality among under-five children is higher among single- parent families than monogamous and polygamous families (Bobak, Pikhart and Koupilova, 2000; Wen, 2008; Lesley, 2008; PRB, 20I0; Doctor, 20II). Other studies reported higher risk of under-five mortality among polygamous families (Hadley, 2005; Gibson \& Mace, 2007; Gyimah, 2009; Kayode, Adekanmbi \& Uthman, 20I2). In addition, variation in under-five mortality has also been observed among different ethnic groups. In Great Brittain for instance, Smith (2000) reported that minority ethnic groups were found to be more socioeconomically disadvantaged than the majority White British population and as a result more likely to have poor health outcomes. Corroborating this finding, Adedini et al (20 II) and Antai (20II) found that women from different ethnic groups in Nigeria experienced different levels of under-five mortality. However, none of these studies used family type and ethnicity as their key variables. In addition, the current study assessed the joint effects of family type and ethnicity on under-five mortality.

\section{Data and methods \\ The study setting}

This study was conducted in Nigeria the most populous countries in Africa. It has a population of about 190 million people (PRB, 2017). The country has about 350 ethnic groups but the three major ones are the Hausas, Igbo and Yoruba (NPC Nigeria and ICF Int., 20I4). Each of these ethnic groups holds on to their cultural identity irrespective of their location within the country and their educational advancement. The Hausas are predominantly Muslims while Igbos and Yorubas are mainly Christians. It is worthwhile to note higher childhood mortality among Muslims than Christians (Adebowale et al, 20I2; Adedini, 20I4). Culturally, monogamy and polygamy are practised in Nigeria. Although very few people are into single-parenting which either resulted from marriage dissolution or loss of spouse/partner (Adenike, 20l3).

\section{Sample design and data collection}

This study utilised the 2013 Nigerian Demographic Health Survey (NDHS) data. The NDHS was cross sectional in design and a nationally representative survey based on a stratified three-stage cluster sampling procedures. A total of 31,828 weighted live births for women of childbearing ages, five years preceding the survey were selected for this study.

\section{Measurement of variables}

The dependent variable in this study is under-five mortality (i.e. death between the ages of 0 and the 59 months). In the NDHS datasets, under-five mortality is measured using the information from the birth 
histories of women age 15-49 years. Questions were asked on the number of children the women have had and whether the children were alive or dead; child's sex; child's current age; age at death if the child had died etc. Under-five mortality was estimated for the five years preceding the survey. All children between 0 and 59 months of age were included in the estimation while all children who stayed alive beyond 59 months of age were removed from the sample. The independent variables in this study are the family type, ethnicity and other socio-economic variables (such as age, education, wealth index, residence, religion, etc) and health variables (Preceding birth interval, antenatal care, Place of delivery, Current use of family planning by method type, etc). Important and relevant variables from the NDHS data were re-classified for the purpose of this study. For instance, age of respondents was reclassified into three: 15-24 years, 25-34 year and 35 years and above; while religion was re-classified into three major groups: Christianity, Islam and Traditional religion

\section{Data analyses}

Descriptive statistics were used to examine the distribution of respondents by selected socioeconomic and health variables. At bivariate level, Pearson chi-square test (McHugh, 20I3) was used in analysing the relationship between under-five mortality (outcome variable) and the explanatory variables (family type and ethnicity). The dependent variable which is under-five mortality is dichotomous ( $I$ if child is alive and 0 if child is dead).In addition, Brass indirect estimation technique was used to estimate under-five mortality rates.

The basic form of the Brass estimation equation is $q(x)=k(i) D(i)$, where $q(x)$ is the probability of dying between exact age $\mathrm{x}$ and $x+n$; and the multiplier $k(i)$ is meant to adjust the non-mortality factor determining the value of $D(i)$.

$$
\begin{gathered}
D(i)=\frac{C D(i)}{C E B(i)} ; \\
k(i)=a(i)+b(i) \frac{P(1)}{P(2)}+c(i) \frac{P(2)}{P(3)} \\
P(i)=\frac{C E B(i)}{F P(i)}
\end{gathered}
$$

The multipliers $k(i)$ being selected according to the value of $\frac{P(1)}{P(2)}$, which is a good indicator of fertility conditions at younger ages - where $P(i)$ is the average parity or average number of children ever born of women of age group i, $\operatorname{CEB}(i)$ is the total number of children ever borne by these women, and
$F P(i)$ is the total number of women in the agegroup and $C D$ is the number of children that died. The survivorship probabilities obtained from the procedures outlined earlier were smoothed by use of regression techniques and Brass's General African Standard Life Table. In order to estimate $\alpha$, average values of $I(2), I(3)$ and $I(5)$ were used $(I(2), I(3)$ and $I(5)$ are the probabilities of surviving from birth to exact ages 2,3 and 5 respectively). Thereafter, $\alpha$ was substituted in the equation logit logit $I(x)=\alpha+$ logit $I s(x)$ to smooth the raw values of $I(x)(I s(x)$ is the probability of surviving to exact age $x$ of a standard life table). This was repeated for each round of the NDHS. The implied expectation of life at birth $(\mathrm{e} 0)$ and mortality rate were read off from the West Model of the Coale-Demeny Model Life tables and by linear interpolation when appropriate. and were implemented in SPSS while was implemented using MORTPAK FOR WINDOW. MORTPAK is a software package that was developed by the United Nations for demographic estimations (United Nations Population Division, 2003). (United Nations Population Division, 2003).

At the multivariate level, data were analyzed using the STATA software version 12.The Cox proportional hazard regression models was used to assess the unadjusted and adjusted influence of family type and ethnicity on under-five mortality. Cox proportional hazards regression analysis is suitable for analysing time-to-event data and censored observations. It is also a robust" model, so that the results from using the Cox model will closely approximate the results for the correct parametric model. In addition, the estimated hazard can be estimated using minimum assumption; and the estimated hazards are always non-negative. One of the assumptions of the model is that the baseline hazards for the sub-groups were proportional with follow-up time. The occurrence of under-five mortality and the time when the child died were both considered as the outcome variables. The time between birth and death of a child under the age of five years or the censored observation is regarded as the survival time. It was assumed that Nigerian mortality pattern is similar to that expressed in the General African Standard on the logit scale

The Cox proportional hazard model is given as:

$\mathrm{h}(\mathrm{t}, \mathrm{X})=\mathrm{h} 0(\mathrm{t}) \exp \left(\sum_{i=1}^{p} \beta_{i} X_{i}\right)$,

where $X=\left(X_{1}, X_{2}, \ldots . . X p\right)$ are explanatory variables included in the model and $\beta_{i}, i=I, 2,3 \ldots p$, are the model parameters. In the Cox regression analysis, the number of months a child has lived will be used as response to the time variable. However, by dividing both sides of equation $\mathrm{I}$ by $\mathrm{hO}(\mathrm{t})$ and taking logarithms, the equation I becomes: 


$$
\left.\frac{h(t, X)}{h_{o}(t)}\right)=\left(\sum_{i=1}^{p} \beta_{i} X_{i}\right)
$$

Where $\left.\frac{h(t, X)}{h_{o}(t)}\right)=\left(\sum_{i=1}^{p} \beta_{i} X_{i}\right)$ is regarded as the hazard ratio. The coefficients bi...bp are estimated by Cox regression.

In order to further explain the risks of under-five mortality among different family types in Nigeria, three models were fitted. The first model explains the influence of family type on under-five mortality, as well as the influence of ethnicity on under-five mortality. The second model explains the adjusted effects of ethnicity on under-five mortality after controlling for family type variable. The third model was fitted to assess the influence of family type and ethnicity on under-five mortality after controlling for socio-economic and health-related factors.

\section{Results}

Distribution of under-five mortality by sociodemographic factors

Table I shows the distribution of under-five mortality by socio-demographic factors. From the results of this study, the mean age of respondents was 29.5 years. Women aged $25-39$ years reported the lowest under-five mortality $(8.0 \%)$ while women aged 15 24 years reported the highest under-five mortality (9.6\%). Under-five mortality decreases as mother's educational status increases: from $10.7 \%$ among women with no formal education to $4.4 \%$ among those who had secondary education or higher. Similarly, under-five mortality decreases as the wealth status of the women increases. It decreases from $11.3 \%$ among the poorest women to $4.59 \%$ among the richest women. A lower under-five mortality of $7.9 \%$ was found among monogamous families, while those in polygamous families and single-parent families exhibit higher under-five mortality of $10.3 \%$ and $9.7 \%$ respectively. Underfive mortality was found to be the least explained by mothers who belong to Yoruba ethnic group (6.0\%) and highest among the Hausa ethnic group (10.7\%). In addition, UFM is higher in rural (10.1\%) than urban $(6.1 \%)$ areas and mortality is higher among male children.

Table I: Distribution of under-five mortality by socio-demographic factors

\begin{tabular}{|c|c|c|c|}
\hline \multirow[b]{2}{*}{ Variable } & \multicolumn{3}{|c|}{ Under-five mortality } \\
\hline & Frequency & Percentage & P-value \\
\hline Age & & & $<0.001$ \\
\hline \multicolumn{4}{|c|}{$x^{-}=29.5$} \\
\hline $15-24$ & 689 & 9.60 & \\
\hline $25-39$ & 1167 & 8.00 & \\
\hline $40-49$ & 708 & 9.40 & \\
\hline \multicolumn{4}{|l|}{ Education } \\
\hline Higher & 1542 & 10.7 & $<0.001$ \\
\hline None & 502 & 8.8 & \\
\hline Primary & 444 & 5.9 & \\
\hline Secondary & 75 & 4.4 & \\
\hline \multicolumn{4}{|l|}{ Working status } \\
\hline Not Currently Working & 838 & 9.19 & \multirow[t]{2}{*}{0.090} \\
\hline Currently Working & 1726 & 8.50 & \\
\hline \multicolumn{4}{|l|}{ Religion } \\
\hline Christianity & 758 & 7.03 & \multirow[t]{3}{*}{$<0.001$} \\
\hline Islam & 183 & 9.70 & \\
\hline Traditional and Others & 23 & 8.54 & \\
\hline \multicolumn{4}{|l|}{ Place of residence } \\
\hline Urban & 633 & 6.11 & \multirow[t]{2}{*}{$<0.001$} \\
\hline Rural & | 931 & 10.12 & \\
\hline \multicolumn{4}{|l|}{ Wealth index } \\
\hline Poorest & 781 & 11.26 & \multirow[t]{5}{*}{$<0.001$} \\
\hline Poorer & 778 & 11.44 & \\
\hline Middle & 413 & 7.51 & \\
\hline Richer & 366 & 6.99 & \\
\hline Richest & 227 & 4.59 & \\
\hline
\end{tabular}




\begin{tabular}{|c|c|c|c|}
\hline North Central & 279 & 7.10 & \multirow[t]{6}{*}{$<0.001$} \\
\hline North East & 495 & 9.58 & \\
\hline North West & 1170 & 10.66 & \\
\hline South East & 217 & 8.50 & \\
\hline South South & 159 & 5.99 & \\
\hline South West & 244 & 5.87 & \\
\hline \multicolumn{4}{|l|}{ Family Type } \\
\hline Monogamous & 118 & 7.9 & $<0.001$ \\
\hline Single Parent & 1500 & 9.7 & \\
\hline Polygamous & 945 & 10.3 & \\
\hline \multicolumn{4}{|l|}{ Ethnicity } \\
\hline Yoruba & 200 & 6.00 & $<0.001$ \\
\hline Hausa/Fulani & 1375 & 10.70 & \\
\hline lgbo/lbo & 244 & 7.50 & \\
\hline Others & 746 & 7.50 & \\
\hline \multicolumn{4}{|l|}{ Children ever born } \\
\hline $1-2$ & 614 & 7.27 & \multirow[t]{4}{*}{$<0.001$} \\
\hline $3-4$ & 720 & 7.91 & \\
\hline $5+$ & 1229 & 10.35 & \\
\hline \multicolumn{3}{|l|}{ Sex of child } & \\
\hline Male & 1369 & 9.25 & \multirow[t]{2}{*}{$<0.001$} \\
\hline Female & 1195 & 8.17 & \\
\hline \multicolumn{4}{|c|}{ Age at birth of first child } \\
\hline Less than 25 years & 2299 & 8.89 & \multirow[t]{2}{*}{0.020} \\
\hline 25 Years and above & 265 & 7.43 & \\
\hline
\end{tabular}

The results (Figure I) further showed 169, 127 and 189 deaths per thousand live births among singleparents monogamous and polygamous families respectively. Among the ethnic groups in the country, under-five mortality rate was 92,119 and 196 deaths per thousand live births among the Yoruba, the Igbo/lbo and the Hausa/Fulani respectively. In the interactive form, the overall distribution of under-five mortality among women of different family type and ethnic backgrounds as shown in Figure I shows that single-parents Hausa/Fulani women reported the highest under-five mortality rate of 265 deaths per 1000 live births, while the polygamous Igbo/lbo women reported the lowest under-five mortality rate of 2 deaths per 1000 live births. 


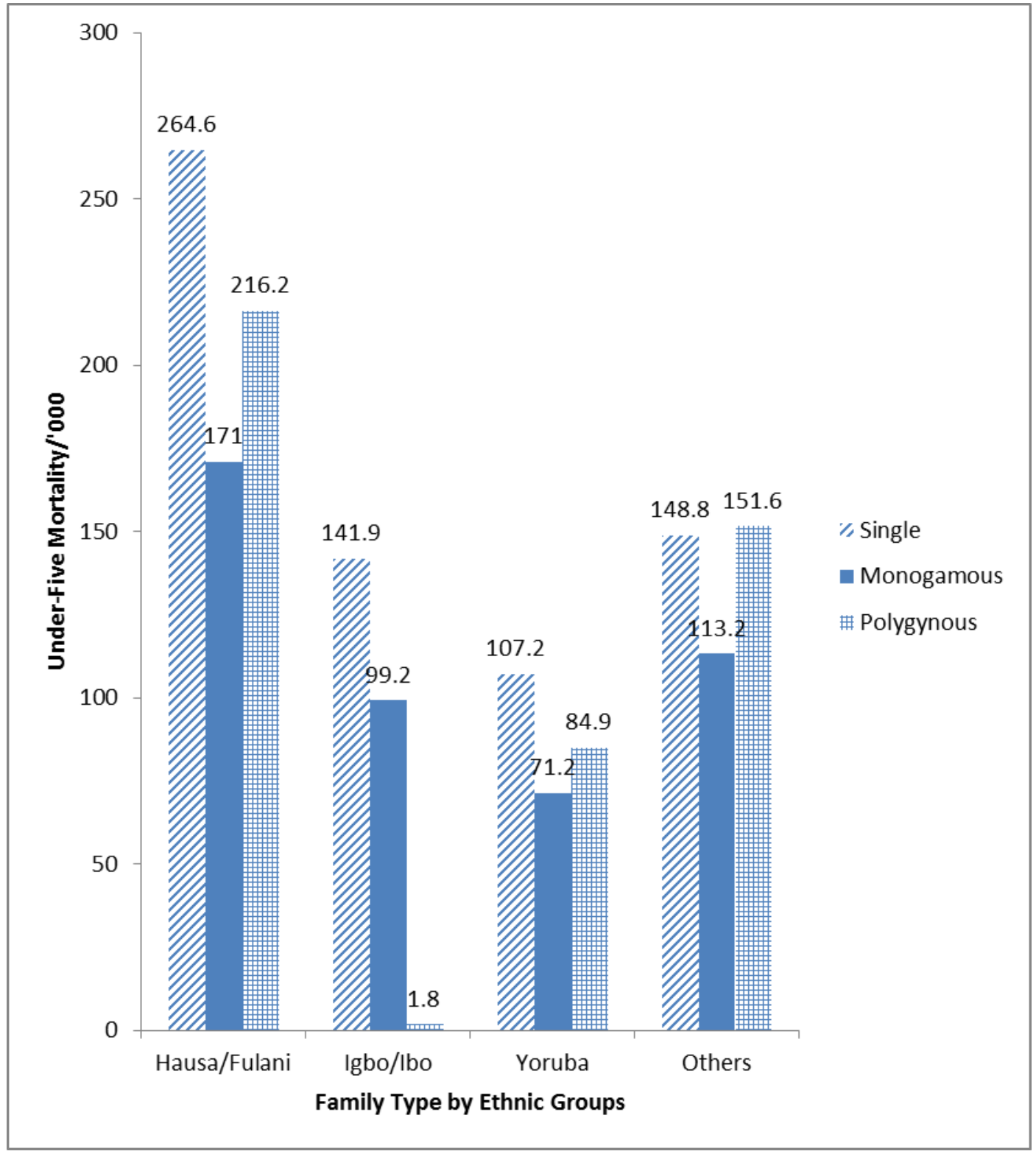

Figure I: Under-five mortality differential by family type and ethnic groups

Hazard ratio and $95 \%$ confidence interval $(\mathrm{Cl})$ of selected factors associated with under-five mortality

Table 2 presents the significant effect of family type, ethnicity and selected socio-demographic variables on under-five mortality. The result indicated that single-parent families $(\mathrm{HR}=1.2343 ; \mathrm{Cl}=1.0082-$ I.5 III) and those in polygamous families $(H R=1.2943 ; p=I .1796-I .4202)$ were more likely to experience under-five mortality than monogamous families. In addition, children of mothers from singleparent families and polygamous families were found to be I. $2(p<0.05)$ and I. 3 times $(p<0.05)$ more likely to die before age five respectively when compared with children from monogamous families.

Also, the Hausa/Fulani women were found to be the most likely to experience under-five mortality, followed by the lgbos/lbos and other minority ethnic groups and finally the Yorubas. While women from the Hausa/Fulani ethnic background were 82 percent more likely to experience under-five deaths than the Yoruba women, the Igbo/lbo women were 27 percent more likely to experience under-five deaths than the Yoruba women; and women from other minority tribes were also 23 percent more likely to experience under-five deaths than women from the Yoruba ethnic group.

In the second model, family type and ethnicity were found to be significantly associated with underfive mortality. The results indicated that single-parent families were 30 percent more likely to experience under-five mortality than monogamous families whereas polygamous families were 17 percent more likely to experience under-five mortality than monogamous families. Women of Hausa/Fulani ethnic background were 82 percent more likely to experience under-five mortality than Yoruba women.

Also, Ibo/lgbo women were 27 percent more likely to experience under-five mortality than Yoruba families. 
The last model explains the influence of family type and ethnicity on under-five mortality while controlling for socio-economic and health-related factors. The result according to Table 2 shows that maternal age, maternal education, residence, children ever born, birth within five years preceding the survey, child's sex, size of child at birth, preceding birth interval, post natal check within two months of delivery contribute to the survival of the under-five children in Nigeria. Female children were also found to be 20 percent less likely to die than their male counterparts. The identified predictors of U5M at $p \leq$
0.005 were maternal age, education, family type, ethnicity, religion, place of residence, region, number of children ever born, sex of the child, age at first birth, size of child at birth, birth interval, place of delivery and current use of family planning method. The likelihood of U5M was significantly lower among women with secondary education $(\mathrm{HR}=0.73 ; \mathrm{Cl}=$ $0.5 \mathrm{I}-\mathrm{I} .04)$ than those with no formal education women in monogamous family $(\mathrm{HR}=0.76 ; \mathrm{Cl}=0.62$ $0.94)$, Yoruba ethnic group $(\mathrm{AOR}=0.57 ; \mathrm{Cl}=0.47$ $0.68)$ than women in Islamic religion $(\mathrm{HR}=0.78 ; \mathrm{Cl}=$ 0.56-I.06) compared with Christian religion.

Table 2: Hazard ratio and $95 \%$ confidence Interval $(\mathrm{Cl})$ of selected factors associated with under-five mortality

\begin{tabular}{|c|c|c|c|c|c|c|}
\hline & \multicolumn{2}{|l|}{ Model I } & \multicolumn{2}{|c|}{ Model II } & \multicolumn{2}{|c|}{ Model III } \\
\hline & HR & $95 \% \mathrm{Cl}$ & HR & $95 \% \mathrm{Cl}$ & HR & $95 \% \mathrm{Cl}$ \\
\hline \multicolumn{7}{|l|}{ Family Type } \\
\hline Monogamous & $\mathrm{RC}$ & - & $\mathrm{RC}$ & - & $\mathrm{RC}$ & \\
\hline Single Parent & $1.2343^{*}$ & $\begin{array}{l}1.0082- \\
1.5111\end{array}$ & $1.308^{*}$ & I.067-I.603 & 1.306 & $0.901-1.893$ \\
\hline Polygamous & I.2943* & $\begin{array}{l}\text { I.I796- } \\
1.4202\end{array}$ & $1.169 *$ & $1.06 \mid-1.289$ & 1.115 & $0.938-1.325$ \\
\hline \multicolumn{7}{|l|}{ Ethnicity } \\
\hline Yoruba & $\mathrm{RC}$ & - & $\mathrm{RC}$ & - & $\mathrm{RC}$ & \\
\hline Hausa/Fulani & $\mathrm{I} .823 \mathrm{I} *$ & $\begin{array}{l}1.5142- \\
2.1950\end{array}$ & $1.766 *$ & $1.464-0.129$ & 0.7968 & $\begin{array}{l}0.4817- \\
1.3181\end{array}$ \\
\hline Igbo/lbo & $1.2686 *$ & $\begin{array}{l}1.0111- \\
1.5918\end{array}$ & $1.283 *$ & $1.021-.6123$ & 0.505 & $0.247-|.03|$ \\
\hline Others & $1.2473^{*}$ & $\begin{array}{l}1.0281- \\
1.5133\end{array}$ & $1.231 *$ & $1.015-1.494$ & 0.673 & $0.422-1.074$ \\
\hline \multicolumn{7}{|l|}{ Age Group } \\
\hline $15-24$ & & & & & $\mathrm{RC}$ & - \\
\hline $25-39$ & & & & & 1.027 & $0.792-1.333$ \\
\hline $40-49$ & & & & & $1.412 *$ & $1.013-1.968$ \\
\hline \multicolumn{7}{|c|}{ Highest educational level } \\
\hline Higher & & & & & $\mathrm{RC}$ & \\
\hline None & & & & & 1.137 & $0.660-1.958$ \\
\hline Primary & & & & & 1.111 & $0.659-1.873$ \\
\hline Secondary & & & & & 0.833 & $0.5|0-| .36 \mid$ \\
\hline \multicolumn{7}{|c|}{ Partner's level of education } \\
\hline Higher & & & & & $\mathrm{RC}$ & \\
\hline None & & & & & 0.910 & $0.623-|.33|$ \\
\hline Primary & & & & & 1.046 & $0.720-1.520$ \\
\hline Secondary & & & & & 0.967 & $0.688-1.360$ \\
\hline \multicolumn{7}{|l|}{ Religion } \\
\hline Christianity & & & & & $\mathrm{RC}$ & \\
\hline Islam & & & & & 0.742 & $0.547-I .005$ \\
\hline Traditional & & & & & 0.630 & $0.292-1.356$ \\
\hline
\end{tabular}


African Population Studies Vol 32, No. 3, Dec. 2018

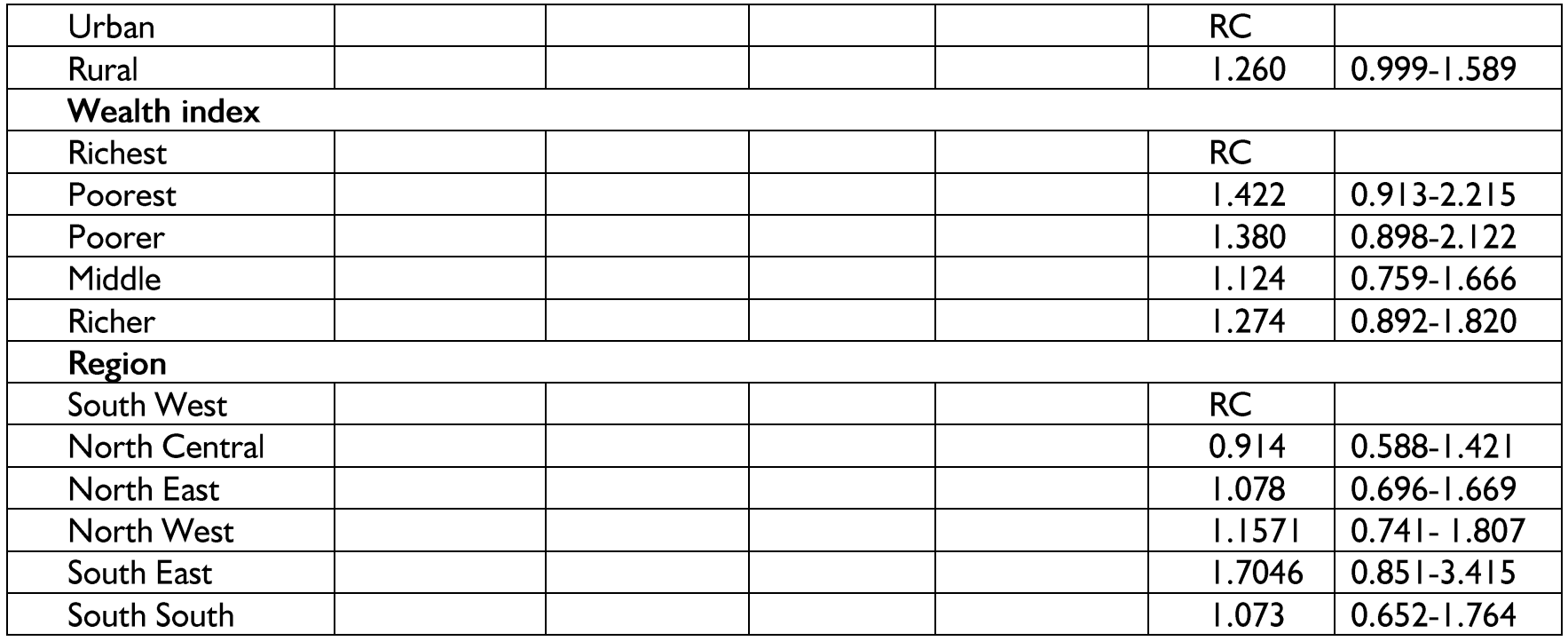

Table 2 (contd.): Hazard ratio and $95 \%$ confidence interval $(\mathrm{Cl})$ of selected factors associated with under-five mortality

\begin{tabular}{|c|c|c|c|c|c|c|}
\hline 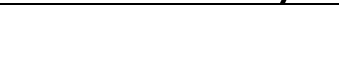 & \multicolumn{2}{|c|}{ Model I } & \multicolumn{2}{|c|}{ Model II } & \multicolumn{2}{|c|}{ Model III } \\
\hline & HR & $95 \% \mathrm{Cl}$ & HR & $95 \% \mathrm{Cl}$ & HR & $95 \% \mathrm{Cl}$ \\
\hline \multicolumn{7}{|l|}{ Children ever born } \\
\hline $1-2$ & & & & & $\mathrm{RC}$ & \\
\hline $3-4$ & & & & & $0.763^{*}$ & $0.594-0.981$ \\
\hline $5+$ & & & & & 0.891 & $0.66 \mathrm{I}-\mathrm{I} .20 \mathrm{I}$ \\
\hline \multicolumn{7}{|c|}{ Births in the last five years } \\
\hline $1-2$ & & & & & $\mathrm{RC}$ & \\
\hline $3+$ & & & & & $2.0339 *$ & $1.546-2.677$ \\
\hline \multicolumn{7}{|l|}{ Sex of child } \\
\hline Male & & & & & $\mathrm{RC}$ & \\
\hline Female & & & & & $0.7960 *$ & $0.681-0.930$ \\
\hline \multicolumn{7}{|c|}{ Preceding birth interval } \\
\hline 4 years + & & & & & $\mathrm{RC}$ & \\
\hline$<2$ years & & & & & $1.416 *$ & $1.083-1.852$ \\
\hline $2-4$ years & & & & & $1.280 *$ & $1.023-1.602$ \\
\hline \multicolumn{7}{|c|}{ Antenatal visits for pregnancy } \\
\hline I-4 Visits & & & & & $\mathrm{RC}$ & \\
\hline No ANC Visit & & & & & 0.947 & $0.746-I .202$ \\
\hline 5 Visits + & & & & & 0.997 & $0.784-1.267$ \\
\hline \multicolumn{7}{|l|}{ Place of delivery } \\
\hline Hospital/Clinics & & & & & $\mathrm{RC}$ & \\
\hline Home & & & & & 0.879 & $0.684-|| 3 \mid$. \\
\hline Others & & & & & 0.688 & $0.092-5.167$ \\
\hline \multicolumn{7}{|c|}{ Current use of family planning by method type } \\
\hline Modern method & & & & & $\mathrm{RC}$ & \\
\hline No method & & & & & 1.4204 & $0.978-2.062$ \\
\hline Traditional method & & & & & 1.217 & $0.720-2.055$ \\
\hline
\end{tabular}

*Significant

$\mathrm{RC}=$ Reference Category 


\section{Discussion}

All over the world, high rate of under-five mortality has implication on national development. In Nigeria, despite some notable advances in health services, the under-five mortality is still considered to be high when compared to some other developing countries in Africa sub-regions. The high under-five mortality rate in Nigeria has been source of concerns to the government and international agencies. This had prompted researchers to investigate factors responsible for under-five mortality in the country. Unfortunately, very few of these studies have included family type and ethnicity as their key variables as found in the current study

This study was carried out to assess the influence of family type and ethnicity on under-five mortality in Nigeria. Women of low educational status were found reporting more under-five mortality than women of high educational status. This finding corroborates some earlier findings by Fayehun and Omololu (20I I). In their findings, they found that under-five mortality decreases with as the level of women's education increases. For instance, the hazards of under-five mortality among uneducated women fell from I.I4 to 0.83 among highly educated women; this finding was similar to that Titilayo et al (2009) who observed that women education is an important factor in reducing under-five mortality. Similarly, under-five mortality decreases as the wealth status of women increases. This is in line with the findings of United Nations Children's Fund (UNFPA, 20I0).

Under-five mortality was found to vary by family type and ethnicity in Nigeria. We found the lowest under-five mortality rate among the monogamous families, an indication that the presence of both parents may contribute immensely to child survival as remarked by Bramlett \& Blumberg (2007). This finding was also similar to that of Wen (2008) and Bramlett \& Blumberg (2007). Similarly, single-parent families exhibit the highest under-five mortality while the monogamous families exhibit the lowest underfive mortality rate. In addition, women from polygamous family were found to be more likely to experience under-five mortality than their counterparts. This finding corroborates earlier finding by Kayode et al (2016).

Under-five mortality was also found to be low among the Yoruba ethnic group and highest among Hausa/Fulani in the country. This low rate of underfive mortality among the Yoruba might be unconnected with the high level of development brought by the early western education in the Western part of the country. According to (Jeffrey, 2005), societies with high level social and economic development tend to experience low under-five mortality. In addition, women from Hausa/Fulani ethnic group were found to be more likely to experience under-five mortality in the future among all the ethnic groups in Nigeria. This finding corroborates the earlier findings by Adedini et al (2015)

In addition, single-parent Hausa/Fulani women reported the highest rate of under-five mortality rate while the polygamous lgbo/lbo women reported the lowest rate of under-five mortality. As might be expected, one will expect polygamous lgbo/lbo women to report high rate of under-five mortality as reported in many studies (Omariba and Boyle, 2007; Kayode et al, 2012) that under-five mortality is generally high among polygamous families. Maternal age, children ever born, sex of the child, age at first birth, size of child at birth, preceding birth interval and baby post-natal check were also found to be significantly associated with under-five mortality in the study area.

\section{Implication of findings}

The outcomes of this study imply that both family type and ethnicity are major factors influencing under-five mortality in Nigeria.

\section{Limitation of the study}

A causal inference cannot be ascertained on the effects of family type and ethnicity on under-five mortality because of the cross-sectional nature of the NDHS data.

\section{Conclusion}

Under-five mortality rate is a critical/major indicator of development in any country. Despite that underfive mortality is decreasing globally and in many countries of the world, African countries still exhibit shocking mortality rates. In the present study, family type and ethnicity were found to be associated with under-five mortality. In particular, our study confirmed that under-five mortality is high in Nigeria, most especially among the Hausa/Fulani and families with single-parents. This matter for any policy and programming aimed at reducing under-five mortality in Nigeria. Hence, a multidimensional approach to further reduce the level of under-five mortality in the country should target single-parenting and ethnic factors.

\section{Declaration}

Ethical approval: The survey procedures and instruments used for the 2013 NDHS survey received ethical approval from the National Ethics Committee in the Federal Ministry of Health, Nigeria and the Ethics Committee of the Opinion Research Corporation Macro International, Inc., USA. 
(Assigned Number: NHREC/0I/0I/2007). The researcher, therefore, sought the ethical permission from ICF Macro Inc. before using this set of data.

Funding: No funding for this research

Competing interest: The authors declare that they have no conflict of interest

Authors contribution: Gbadebo B.M conceived and developed the research proposal, reviewed literatures, analysed the data and wrote the results. Bamiwuye S.O contributed to literature review and the analyses of data. Bisiriyu L.A contributed to data analyses and result writing.

Acknowledgment: The authors acknowledge the National Population Commission (Nigeria) and ICF International (USA) for giving us access to 2013 NDHS data for this study.

\section{References}

Adebowale, A.S, Yusuf, B.O and Fagbamigbe, A. F. 2012. Survival probability and predictors for woman experience childhood death in Nigeria: analysis of north-south differentials. BMC Public Health, 12: 430.

Adedini, S.A. (2014). Neighbourhood characteristics and under-five mortality in Nigeria. African Population Studies, 27(2), Supplement.

Adedini, S.A, Odimegwu, C. O., Imasiku, E.N.S., Ononokpono, D., and Timiun G. G. A. (20II). Inequality in Under-Five Mortality in Nigeria: do ethnic values and cultural practices matter? Paper delivered at Sixth African Population Conference.

Adedini, S.A, Odimegwu,C, Imasiku, E.N.S. \& Ononokpono. D.N. (20I5).Ethnic differentials in under-five mortality in Nigeria. Ethnicity \& Health, 20(2): I45-162.

Adenike O.A. 2013. Effect of family type(monogamy or Polygamy) on students' academic achievement in Nigeria. International Journal of Psychology and Counselling, 5(7): I53-I56.

Antai, D. (20II). Regional Inequalities in Under-Five Mortality in Nigeria: a Population-Based Analysis of Individual- and community-Level Determinants. Population Health Metrics, 9(6): I-27.

Bobak, M., Pikhart, H. and Koupilova, I. (2000). Maternal Socio-Economic Characteristics and Infant Mortality from Injuries in the Czech Republic 1989-92. Inj Prev.; 6:195-198. doi: 10.1136/ip.6.3.195. [PMC free article][PubMed] [Cross Ref]

Bramlett, M. \& S. Blumberg. (2007). Family structure and children's physical and mental health. Health Affairs, 26(2): 549-558.
Bryce, J., Boschi-Pinto, C., Shibuya, K., Black, R.E. and the WHO Child Health Epidemiology Reference Group. (2005). WHO Estimates of the Causes of Death in Children. Lancet; 365: II4752. [PubMed].

Doctor, H.V. (20II). Does Living in a FemaleHeaded Household Lower Child Mortality? The Case of Rural Nigeria. Rural Remote Health, II (2): 1635.

Fayehun O. and Omololu O. (20II). Ethnicity and Child Survival in Nigeria. African Poppulation Studies; 25(I), (Supplement)

Gyimah, S. O. (2002). Ethnicity and Infant Mortality in Sub-Saharan Africa: The Case of Ghana. Population Studies Centre Discussion Paper Number 02-10. The University of Western Ontario: London, Ontario, Canada.

Jeffrey, D.S. (2015). Can extreme poverty be eliminated? Scientific American

Jegede, A. S., Ajala A. S., Adejumo, O. P. and Osunwole, S. O. (2006).

Forced Feeding Practice in Yoruba Community of Southwestern Nigeria: Evidence from Ethnographic Research. Anthropologist, 8(3): I7I179.

KandalaN.B., Ji C., Stallard N. Stranges $S$ and Cappucicio F.P. (2007). The Spatial Ananlysis of the Risk Factors for Childhood Morbidity in Nigeria. Am. J.Tropp. Med Hyg, 77(4), Pp 770778

Kayode, G. A., Adekanmbi, V. T. and Uthman, O. A. (20/2). Risk Factors and a Predictive Model for Under-Five Mortality in Nigeria: Evidence from Nigeria Demographic and Health survey. BMC Pregnancy and Childbirth, 12:10

Kayode GA, Grobbee DE, Koduah A, AmoakohColeman M, Agyepong IA, Ansah E, van Dijk H, Klipstein-Grobusch K. (20I6). Temporal trends in childhood mortality in Ghana: impacts and challenges of health policies and programs. Glob Health Action. doi:I0.3402/gha.v9.31907. eCollection 2016.

Lesley, K. (2008). Lone Parent Family with Young Children: Findings from the Growing $U p$ in Scotland Study. October.

McHugh M.I. (20I3). The chi-square test of independence. Biochem Med(Zagreb), 23(2): I43149.

Mutunga, J.C. (2004). Environmental Determinants of Child Mortality in Urban Kenya. Discussed in an informal workshop held at the Abdus Salam ICTP: Trieste, Italy

National Population Commission (NPC) [Nigeria] and ORC Macro. (1991). Nigeria Demographic and Health Survey 1990. Calverton, Maryland: National Population Commission and ORC Macro. 
National Population Commission (NPC) [Nigeria] and ORC Macro. (2000).

Nigeria Demographic and Health Survey 1999. Calverton, Maryland: National Population Commission and ORC Macro.

National Population Commission (NPC) [Nigeria] and ORC Macro. (2004).

Nigeria Demographic and Health Survey 2003. Calverton, Maryland: National Population Commission and ORC Macro.

National Population Commission (NPC) (Nigeria) and ICF Macro. (2009).

Nigeria Demographic and Health Survey 2008. Abuja, Nigeria: National Population Commission and ICF Macro.

National Population Commission (NPC) [Nigeria] and ICF International.

(20/4). Nigeria Demographic and Health Survey 2013. Abuja, Nigeria, and Rockville, Maryland, USA: NPC and ICF International.

Ogunjuyigbe, P. O. (2004). „Under-Five Mortality in Nigeria: Perception and Attitude of the Yoruba towards the Existence of Abiku". Demographic Research, II (2).

Oleribe O.O and Taylor-Robinson S.D. (2016). Before Sustainable Development Goals: Why Nigeria Failed to Achieve Millennium Development Goals. The Pan African Medical Journal, 24, I56

Omariba, D., Walter, R. B. and Michael, H. (2007). Family Structure and Child Mortality in SubSaharan Africa: Cross-National Effects of Polygyny. Journal of Marriage and Family, 69(2):528-543; May.

Population Reference Bureau. (2010). U.S. Children in Single-Mother Families. Data Brief. May
African Population Studies Vol 32, No. 3, Dec. 2018

Population Reference Bureau. (2017). World Population Data Sheet

Shudy, M., de Almeida, M. L., Ly, S., Landon, C., Groft, S., Jenkins, T. L.,

MSN, RN, CCRN,Nicholson C.E, MD. (2006). Impact of Pediatric Critical Illness and Injury on Families: A systematic Literature Review. Pediatrics, I 8 (Suppl 3): S203-S2 I8.

The UN- Inter-agency Group for Child Mortality Estimation (IGME). (20I0). Level \& Trends in Child Mortality

The World Bank. (2010). Mortality Rate, Under-5 (per 1000 live births). Data/Table. http://data.worldbank.org/indicator/SH.DYN.MO RT

Titilayo A., Obiyan M., Agunbiade O. M. and Fasina F.F. (2009). Maternal Age at Birth and Under-5 Mortality in Nigeria. East African Journal of Pablic Health, 6 (I), April.

Titilayo A, Anuodo, O.O \& Palamuleni, M.E. (2017). Family Type, domestic Violence and under-five mortality in Nigeria. African Health Sciences, I7(2), 538-548

UNICEF. (20I2). State of the world's children 20I2: children in an urban world.

United Nations Children's Fund (2010). Levels and Trends in Child Mortality Report 2010.Estimates Developed by United Nations Inter-Agency Group for Child Mortality Estimations United Nations Children's Fund. 2010.

Wen, M. (2008). Family Structure and Children's Health and Behavior Data from the 1999 National Survey of America's Families. Journal of Family Issues, 29, 1492-1519

WHO. (2018). Child mortality; Millennium Development Goal (MDG) 4. The Partnership for maternal, Newborn and child Health Fact Sheet 